\title{
KHẢO SÁT NHU CẦU CHĂM SÓC CỦA NGƯờI BÊNHH SAU PHẪU THUÂ̂T TẠI KHỐI NGOẠI BỆNH VIỆn K
}

\begin{abstract}
TÓM TẮT.
Mục tiêu: Xác định nhu câu chăm sóc của người bệnh sau phâ̂u thuật và một số yếu tố liên quan đến nhu câu chăm sóc của người bệnh tại Bệnh viện K. Đối tượng và phương pháp nghiên cứu: Điều tra cắt ngang 389 bệnh nhân sau phâu thuật. Phỏng vấn người bệnh để đánh giá nhu cầu chăm sóc sức khỏe. Kết quả: Nhu câu chăm sóc về y tế, nhu câu chăm sóc về thể chất, tinh thần và xã hội chiếm lần lượt là $86,9 \%, 85,7 \%, 58,1 \%$.Và $56,3 \%$. Một số yếu tố liên quan đến nhu câuu chăm sóc về y tế: nhóm tuổi, diện chi trả. Yếu tố liên quan đến nhu câu chăm sóc tinh thần: tuổi, giới và giai đoạn bệnh. Một số yếu tố liên quan đến nhu cầu chăm sóc về thể chất: giới và trình độ học vấn. Yếu tố liên quan đến nhu câu chăm sóc vể xã hội: trình độ học vấn và nơi cư trú. Kết luận: Người bệnh đều có nhu câu chăm sóc cao.
\end{abstract}

Tư khóa: Phẫu thuật, Nhu câu chăm sóc, Chăm sóc người bệnh.

\section{SUMMARY}

\section{SURVEY OF THE CAREING DEMAND OF THE PATIENTS AFTER SURGERY IN THE BLOCK OF K HOSPITAL}

Objectives: Determine the care needs of the patient after surgery and some factors related to the patient's care needs at K Hospital. Subjects and Method: Cross-sectional investigation of 389 patients after surgery. Interview patients to assess health care needs. Results: The need for medical care, the need for physical, mental and social care accounted for $86.9 \%, 85.7 \%$, and $58.1 \%$, respectively. And $56.3 \%$. Some factors are related to the need for medical care: age group, coverage area. Factors related to mental care needs: age, gender and stage of disease. Several factors are associated with the need for physical care: gender and education level. Factors related to the need for social care: education level and place of residence. Conclusions: Needs care of patients is high

Key words: Surgery, Care needs, Patient care.

\section{I. ĐĂT VẤN ĐỀ}

Trong điều trị bệnh ung thư, ngoài việc điều trị bằng thuốc và các kỹ thuật cao như xạ trị, hóa trị... thì phương pháp phẫu thuật chiếm một vị trí rất quan trọng. Các cuộc phẫu thuật dù là đơn giản hay phức tạp đều gây căng thẳng, lo lắng cho NB và gia đình NB. Người bệnh đều

\footnotetext{
*Bênh viên $K$

Chịu trách nhiệm chính: Nguyễn Thị Thanh Mai

Email: maintvk@gmail.com

Ngày nhân bài: 15.9.2021

Ngày phản biên khoa hoc: 12.11.2021

Ngày duyệt bài: 22.11.2021
}

\section{Nguyễn Thị Thanh Mai*}

phải quyết định để trải qua một cuộc phẫu thuật có liên quan đến đau đớn, có thể thay đổi hình dạng cơ thể, hoăc những tai biến khó lường, thậm chí phải đối đầu với cái chết. Phẫu thuật càng phức tạp thì sự ảnh hưởng của nó tới các cơ quan trong cơ thể càng nhiêuu từ đó NB có nhiều nhu cầu cần phải chăm sóc. Do đó, vai trò chăm sóc hỗ trợ của điều dưỡng là rất quan trọng, người điều dưỡng phải dự đoán trước các nhu cầu này để góp phần vào sự thành công của phẫu thuật. Với mong muốn cải thiện thời gian sống thêm và nâng cao chất lượng sống cho NB ung thư chúng tôi tiến hành nghiên cứu đề tài "Khảo sát nhu cầu chăm sóc của người bênh sau phẫu thuật tại khối ngoại Bệnhviện K"với 2 mục tiêu:

1. Xác định nhu cầu chăm sóc của người bệnh sau phẫu thuật tại bệnh viện $K$

2. Tìm hiểu một số yếu tố liên quan đến nhu cầu chăm sóc của người bệnh sau PT

\section{II. ĐỐI TƯợNG VÀ PHƯƠNG PHÁP NGHIÊN CỨU}

2.1. Đối tượng nghiên cứu: Người bệnh sau phẫu thuật ung thư đang điều trị tại các khoa Ngoai Bệnh viên K. Ngoai trừ NB không tỉnh táo, không hợp tác, câm, điếc, bị bệnh quá nặng, NB được phẫu thuật ở bệnh viện khác chuyển lên Bệnh viện $K$, NB là nhân viên của bệnh viên.

2.2. Phương pháp nghiên cứu: Nghiên cứu mô tả cắt ngang.

\subsection{Cỡ mẫu : 389 người bệnh}

2.4. Phương pháp chọn mẫu: Chon NB tại mỗi khoa ngoại theo phương pháp ngẫu nhiên hệ thống, số NB được chọn tỳ lệ với số NB nằm điều trị tại bệnh phòng, khoa nào có nhiều NB hơn thì có nhiều người được chọn hơn.

2.5. Phương pháp đánh giá: Biến sỗ về nhu cầu CS của NB được xây dựng dựa trên thông tư 07/2011/TT-BYT của Bộ Y tế hướng dẫn công tác điều dưỡng về CSNB trong bệnh viện và được chia thành 4 nhóm theo nội dung CSNB toàn diện của Bộ $Y$ tế: nhu cầu CS về $y$ tế, nhu cầu CS vể thể chất, nhu cầu CS về tinh thần và nhu cầu CS về xã hội. Tổng điểm dựa trên số điểm từng nội dung rồi phân thành 2 nhóm: NB có nhu cầu cao nếu đạt tổng điểm lớn hơn hoăc bằng $1 / 2$ số điểm tối đa và nhu câu thấp nểu tổng điểm dưới 1/2số điểm tối đa. 
III. KẾT QUẢ NGHIÊN CỨU

1. Nhu câu chăm sóc của người bệnh tại khối ngoại Bệnh viện K

Bảng 1. Nhu cầu chăm sóc về y tề

\begin{tabular}{|c|c|c|}
\hline Nhu câu & $\mathbf{n = 3 8 9}$ & Tỷ lệ (\%) \\
\hline $\begin{array}{c}\text { Muốn biết về tình hình } \\
\text { bệnh tật }\end{array}$ & 359 & 92,3 \\
\hline Chăm sóc giảm đau & 352 & 90,4 \\
\hline
\end{tabular}

\begin{tabular}{|c|c|c|}
\hline $\begin{array}{c}\text { Biết cách phòng ngừa } \\
\text { nhiếm trùng }\end{array}$ & 333 & 85,7 \\
\hline Biết cách sữ dụng thuốc & 347 & 89,2 \\
\hline
\end{tabular}

NB muốn biết tình hình bệnh của mình chiếm tỷ lệ cao: 92,3\%, sau đó đến nhu cầu giảm đau, cách sử dụng thuốc, phòng ngừa nhiễm trùng là $90,4 \% ; 89,2 \%$ và $85,7 \%$.

Bảng 2. Nhu cầu chăm sóc về thể chât

\begin{tabular}{|c|c|c|}
\hline Nhu câu & $\mathbf{N = 3 8 9}$ & Tỷ lệ(\%) \\
\hline Hố trợ vệ sinh cá nhân & 275 & 70,8 \\
\hline Hồ trợ về vận động và tập luyện sau PT & 340 & 87,5 \\
\hline Hồ trợ trong sự bài tiết. & 207 & 53,2 \\
\hline Hố trợ mặc và thay quần áo. & 170 & 43,8 \\
\hline Biết chế độ nghi ngơi phù hợp với bệnh. & 328 & 84,3 \\
\hline Biết chế độ ăn phù hợp với bệnh. & 333 & 85,7 \\
\hline HD cách tự chăm sóc, theo dõi, phòng bệnh. & 305 & 78,3 \\
\hline
\end{tabular}

Đa số NB muốn biết về việc hố trơ vận động và tâp luyê̂n, chế độ ăn uống nghỉ ngơi phù hợp, HD cách tự chăm sóc,TD và phòng bệnh là $87,5 \% ; 85,7 \% ; 84,3 \%$ và $78,3 \%$.

Bảng 3. Nhu cầu chăm sóc về tinh thấn

\begin{tabular}{|c|c|c|}
\hline Nhu câu & $n=389$ & Tỷ lệ(\%) \\
\hline Giảm lo lắng sau khi phầu thuật & 328 & 84,3 \\
\hline Giảm lo lắng trước khi tiến hành các thủ thuật. & 297 & 76,4 \\
\hline Hô̂ trợ các hoạt động vui choi, giải trí. & 256 & 65,7 \\
\hline Muốn giữ bí mật về bệnh tật, vấn đề riêng tư. & 127 & 32,6 \\
\hline Hố trợ kiến thức về bệnh của bản thân. & 344 & 88,5 \\
\hline Muốn biết chi phí điều trị hàng ngày. & 326 & 83,7 \\
\hline Muốn có đước giấc ngủ ngon khi nằm viên. & 310 & 79,8 \\
\hline
\end{tabular}

Nhu cầu CS về tinh thần của NB khá cao về hỗ trợ kiến thức về bệnh $88,5 \%$; hỗ trợ đế khỏi lo lắng sau khi phẫu thuật 84,3\%; biết chi phí điêuu trị hằng ngày $83,7 \%$.

Bảng 4. Nhu cầu chăm sóc về xã hội

\begin{tabular}{|c|c|c|}
\hline Nhu câu & $\mathbf{n = 3 8 9}$ & Tỷ lệ(\%) \\
\hline Hố trợ viện phí. & 356 & 91,6 \\
\hline Muốn được tôn trọng. & 342 & 87.9 \\
\hline Muốn được đối xứ công bằng. & 332 & 85,3 \\
\hline Muốn được an toàn khi nằm viện. & 354 & 91,1 \\
\hline Muốn được bày tó quan điếm bản thân. & 252 & 64,7 \\
\hline
\end{tabular}

$\mathrm{NB}$ có nhu câu CS về xã hội cao nhất là muốn hỗ trợ viện phí, an toàn khi nằm viện, tôn trọng, đối xử công bằng, $91,6 \% ; 91,1 \% ; 87,9 \%$ và $85,3 \%$.

Bảng 5. Phân loại các nhu cầu chăm sóc sức khỏe

\begin{tabular}{|c|c|c|c|c|}
\hline \multirow{2}{*}{ Nhu câu } & \multicolumn{2}{|c|}{ Cao } & \multicolumn{2}{c|}{ Thấp } \\
\cline { 2 - 5 } & SL & $\mathbf{\%}$ & $\mathbf{S L}$ & $\mathbf{\%}$ \\
\hline Chăm sóc về y tế & 338 & 86,9 & 51 & 14,1 \\
\hline Chăm sóc về thế chất & 333 & 85,7 & 56 & 14,3 \\
\hline Chăm sóc về tinh thần & 219 & 56,3 & 170 & 43,7 \\
\hline Chăm sóc về xã hội & 203 & 58,1 & 186 & 47,9 \\
\hline
\end{tabular}

NB có nhu cầu cao về chăm sóc y tế, CS thể chất $(86,9 \%$ và $85,7 \%)$, CS tinh thần, CS về xã hội là (56,3\% và $47,9 \%)$.

3. Các yếu tố liên quan đến nhu câu chăm sóc của người bệnh sau phẫu thuật

Bảng 6: Các yếu tố liên quan đến nhu cầu chăm sóc về y tề

\begin{tabular}{|c|c|c|c|c|c|c|}
\hline \multirow{2}{*}{\multicolumn{2}{|c|}{ Yếu tố NCCS về y tế }} & \multicolumn{2}{|c|}{ Cao } & \multicolumn{2}{|c|}{ Thấp } & \multirow{3}{*}{$\begin{array}{c}\text { OR } \\
(95 \% \mathrm{CI})\end{array}$} \\
\hline & & SL & N (\%) & SL & $\%$ & \\
\hline Nhóm tuổi & $<60$ & 308 & 79,1 & 81 & 20,8 & \\
\hline
\end{tabular}




\begin{tabular}{|c|c|c|c|c|c|c|}
\hline & $\geq 60$ & 354 & 90,9 & 35 & 9,1 & $(0,17-0,86)$ \\
\hline \multirow{2}{*}{ Giới } & Nam & 340 & 87,5 & 49 & 12,4 & \multirow{2}{*}{$\begin{array}{c}1,6 \\
(0,76-3,43)\end{array}$} \\
\hline & Nữ & 317 & 81,5 & 72 & 18.5 & \\
\hline \multirow{2}{*}{$\begin{array}{l}\text { Trình độ } \\
\text { học vấn }\end{array}$} & $\leq \mathrm{THCS}$ & 338 & 86,8 & 51 & 13,0 & \multirow{2}{*}{$\begin{array}{c}1,19 \\
(0,33-4,26) \\
\end{array}$} \\
\hline & $\geq \mathrm{PTTH}$ & 330 & 84,8 & 59 & 15,1 & \\
\hline \multirow{3}{*}{$\begin{array}{l}\text { Nghề } \\
\text { nghiệp }\end{array}$} & Nghề nông & 326 & 83,7 & 63 & 16,3 & \multirow{3}{*}{$\begin{array}{c}0,93 \\
(0,42-2,06)\end{array}$} \\
\hline & CBVC & 329 & 84,6 & 60 & 15,4 & \\
\hline & Nghề khác & 254 & 65,3 & 135 & 34,7 & \\
\hline \multirow{2}{*}{ Nơi cư trú } & Nông thôn & 333 & 85,7 & 56 & 14,3 & \multirow{2}{*}{$\begin{array}{c}1,16 \\
(0,54-2,49)\end{array}$} \\
\hline & Thành thi & 327 & 84 & 62 & 16 & \\
\hline \multirow{2}{*}{ Kinh tế } & Cận nghèo, nghèo & 287 & 73,9 & 102 & 26,1 & \multirow{2}{*}{$\begin{array}{c}0,65 \\
(0,24-1,78)\end{array}$} \\
\hline & Không nghèo & 316 & 81,2 & 73 & 18,8 & \\
\hline \multirow{2}{*}{$\begin{array}{l}\text { Giai đoạn } \\
\text { bệnh }\end{array}$} & GĐ I,II & 169 & 43,5 & 220 & 56,5 & \multirow{2}{*}{$\begin{array}{c}1,78 \\
(0,74-4,29)\end{array}$} \\
\hline & GĐ III,IV & 117 & 30,2 & 272 & 69,8 & \\
\hline \multirow{2}{*}{ Diện chi trả } & BHYT & 378 & 97,1 & 11 & 2,9 & \multirow{3}{*}{$\begin{array}{c}7,14^{* *} \\
(2,23-22,73)\end{array}$} \\
\hline & Tự chi trả & 327 & 84 & 62 & 16,0 & \\
\hline & & & 0,05 & & & \\
\hline
\end{tabular}

Có mối liên quan giữa nhu cầu CS y tế với nhóm tuối và diện chi trả $(p<0,05)$. Tỷ lệ nhu cầu này ở nhóm $\geq 60$ tuổi cao hơn nhóm $<60$ tuổi $(\mathrm{OR}=0,39 ; 95 \% \mathrm{CI}=0,17-0,86)$; nhóm có BHYT có nhu cầu $<$ nhóm tự chi trả $(\mathrm{OR}=7,14 ; 95 \% \mathrm{CI}=2,23-22,73)$.

Bảng 7. Các yếu tố liên quan đến nhu cầu chăm sóc về tinh thần

\begin{tabular}{|c|c|c|c|c|c|c|}
\hline \multirow{2}{*}{\multicolumn{2}{|c|}{ Yếu tố $\quad$ NCCS về tinh thần }} & \multicolumn{2}{|c|}{ Cao } & \multicolumn{2}{|c|}{ Thấp } & \multirow{2}{*}{$\begin{array}{c}\text { OR } \\
(95 \% \mathrm{CI})\end{array}$} \\
\hline & & SL & $\%$ & SL & $\%$ & \\
\hline \multirow{2}{*}{ Nhóm tuổi } & $<60$ & 367 & 94,3 & 22 & 5,7 & \multirow{2}{*}{$\begin{array}{c}2,66^{* *} \\
(1,0-7,14)\end{array}$} \\
\hline & $\geq 60$ & 335 & 86,2 & 54 & 13,8 & \\
\hline \multirow{2}{*}{ Giới } & Nam & 331 & 85,1 & 58 & 14,9 & \multirow{2}{*}{$\begin{array}{c}0,22 * * \\
(0,06-0,79)\end{array}$} \\
\hline & Nũ̃ & 375 & 96,5 & 14 & 3,5 & \\
\hline \multirow{2}{*}{$\begin{array}{l}\text { Trình độ } \\
\text { học vấn }\end{array}$} & $\leq \mathrm{THCS}$ & 352 & 90,4 & 37 & 9,6 & \multirow{2}{*}{$\begin{array}{c}1,02 \\
(0,36-2,94)\end{array}$} \\
\hline & $\geq \mathrm{PTTH}$ & 351 & 90.2 & 38 & 9,8 & \\
\hline \multirow{3}{*}{$\begin{array}{c}\text { Nghề } \\
\text { nghiệp }\end{array}$} & Nghề nông & 360 & 92,5 & 29 & 7,5 & \multirow{3}{*}{$\begin{array}{c}1,95 \\
(0,79-4,82)\end{array}$} \\
\hline & CBVC & 336 & 86,4 & 53 & 13,6 & \\
\hline & Nghề khác & 324 & 83,3 & 65 & 16,7 & \\
\hline \multirow{2}{*}{ Nơi cư trú } & Nông thôn & 358 & 92,0 & 31 & 8,0 & \multirow{2}{*}{$\begin{array}{c}1,38 \\
(0,51-3,72)\end{array}$} \\
\hline & Thành thị & 347 & 89,3 & 42 & 10,7 & \\
\hline \multirow{2}{*}{ Kinh tế } & Cận nghèo,nghèo & 367 & 94,4 & 22 & 5,6 & \multirow{2}{*}{$\begin{array}{c}3,81 \\
(1,50-9,69)\end{array}$} \\
\hline & Không nghèo & 318 & 81,7 & 71 & 18,3 & \\
\hline \multirow{2}{*}{$\begin{array}{l}\text { Giai đoạn } \\
\text { bệnh }\end{array}$} & GĐ I,II & 318 & 81,8 & 71 & 18,2 & \multirow{2}{*}{$\begin{array}{c}3,81^{* *} \\
(1,50-9,69)\end{array}$} \\
\hline & GĐ III,IV & 368 & 94,5 & 41 & 5,5 & \\
\hline \multirow{2}{*}{ Diện chi trả } & BHYT & 338 & 87,0 & 51 & 13,0 & \multirow{2}{*}{$\begin{array}{c}0,69 \\
(0,19-2,55)\end{array}$} \\
\hline & Tự chi trả & 352 & 90,6 & 37 & 9,4 & \\
\hline
\end{tabular}

Có mối liên quan giữa nhu cầu CS tinh thần với nhóm tuổi, giới và giai đoạn bệnh $(p<0,05)$. Nhóm từ $\geq 60$ tuổi < nhóm < 60 tuổi $(\mathrm{OR}=2,66 ; 95 \% \mathrm{CI}=1,0-7,14)$; nữ giới > nam giới $(\mathrm{OR}=0,22$; $95 \% \mathrm{CI}=0,06-0,78)$; nhu câu ở nhóm giai đoạn I, II < nhóm giai đoạn III (OR = 3,81; $95 \% \mathrm{CI}=$ $1,50-9,69)$.

Bảng 8. Các yêu tố liên quan đến nhu cầu chăm sóc về thể chất

\begin{tabular}{|c|c|c|c|c|c|c|}
\hline \multirow{2}{*}{\multicolumn{2}{|c|}{ Yếu tố $\quad$ NCCS về thể chất }} & \multicolumn{2}{|c|}{ Cao } & \multicolumn{2}{|c|}{ Thấp } & \multirow{2}{*}{$\begin{array}{c}\text { OR } \\
(95 \% \mathrm{CI})\end{array}$} \\
\hline & & SL & $\%$ & SL & $\%$ & \\
\hline \multirow{2}{*}{ Nhóm tuối } & $<60$ & 301 & 77,4 & 88 & 22,6 & \multirow{2}{*}{$\begin{array}{c}0,68 \\
(0,34-1,33)\end{array}$} \\
\hline & $\geq 60$ & 325 & 83,5 & 64 & 16,5 & \\
\hline \multirow{2}{*}{ Giới } & Nam & 265 & 68,2 & 124 & 31,8 & \multirow{2}{*}{$\begin{array}{c}0,25^{* *} \\
(0,03-0,19)\end{array}$} \\
\hline & Nũ̃ & 384 & 98,8 & 5 & 1,2 & \\
\hline \multirow{2}{*}{$\begin{array}{l}\text { Trình độ } \\
\text { học vấn }\end{array}$} & $\leq \mathrm{THCS}$ & 235 & 60,4 & 154 & 39,6 & \multirow{2}{*}{$\begin{array}{c}8,09 * * \\
(3,7-17,72)\end{array}$} \\
\hline & $\geq \mathrm{PTTH}$ & 360 & 92,5 & 29 & 7,5 & \\
\hline
\end{tabular}


VIETNAM MEDICAL JOURNAL N02 - DECEMBER - 2021

\begin{tabular}{|c|c|c|c|c|c|c|}
\hline \multirow{3}{*}{$\begin{array}{c}\text { Nghề } \\
\text { nghiệp }\end{array}$} & Nghề nông & 7 & 1,9 & 382 & 98,1 & \multirow{3}{*}{$\begin{array}{c}17,14 \\
(2,29-127,97)\end{array}$} \\
\hline & CBVC & 291 & 74,8 & 98 & 25,2 & \\
\hline & Nghề khác & 235 & 60,5 & 154 & 39,5 & \\
\hline \multirow{2}{*}{ Nơi cư trú } & Nông thôn & 329 & 84,5 & 60 & 15,5 & \multirow{2}{*}{$\begin{array}{c}1,49 \\
(0,70-3,18)\end{array}$} \\
\hline & Thành thị & 305 & 78,5 & 84 & 21,2 & \\
\hline \multirow{2}{*}{ Kinh tế } & Cận nghèo,nghèo & 360 & 92,5 & 29 & 7,5 & \multirow{2}{*}{$\begin{array}{c}8,09 \\
(3,7-17,72)\end{array}$} \\
\hline & Không nghèo & 235 & 60,5 & 154 & 39,5 & \\
\hline \multirow{2}{*}{$\begin{array}{l}\text { Giai đoạn } \\
\text { bệnh }\end{array}$} & GĐ I,II & 298 & 76,5 & 91 & 23,5 & \multirow{2}{*}{$\begin{array}{c}1,73 \\
(0,92-3,31)\end{array}$} \\
\hline & GĐ III,IV & 142 & 36,6 & 247 & 63,4 & \\
\hline \multirow{2}{*}{ Diện chi trả } & BHYT & 287 & 73,9 & 102 & 26,1 & \multirow{2}{*}{$\begin{array}{c}0,65 \\
(0,24-1,78)\end{array}$} \\
\hline & Tự chi trả & 316 & 81,2 & 73 & 18,8 & \\
\hline
\end{tabular}

Có mối liên quan giữa nhu cầu CS thể chất với giới và trình đô học vấn $(\mathrm{p}<0,05)$. Tỷ lệ nhu cầu này ở nữ > nam $(\mathrm{OR}=0,25 ; 95 \% \mathrm{Cl}=0,03-0,19)$; nhóm trình độ học vấn $\leq$ THCS < nhóm trình độ $\geq$ PTTH (OR = 8,09; 95\% CI= 3,7-17,72).

Bảng 9. Các yếu tố liên quan đến nhu cầu chăm sóc về xã hội

\begin{tabular}{|c|c|c|c|c|c|c|}
\hline \multirow{2}{*}{\multicolumn{2}{|c|}{ Yếu tố $\quad$ NCCS về xã hội }} & \multicolumn{2}{|c|}{ Cao } & \multicolumn{2}{|c|}{ Thấp } & \multirow{2}{*}{$\begin{array}{c}\text { OR } \\
(95 \% \mathrm{CI})\end{array}$} \\
\hline & & SL & $\%$ & $\mathbf{S L}$ & $\%$ & \\
\hline \multirow{2}{*}{ Nhóm tuổi } & $<60$ & 341 & 87,7 & 48 & 12,3 & \\
\hline & $\geq 60$ & 378 & 97,2 & 11 & 2,8 & $(0,56-0,73)$ \\
\hline \multirow{2}{*}{ Giới } & Nam & 273 & 70,2 & 116 & 29,8 & \multirow{2}{*}{$\begin{array}{c}1,24 \\
(0,68-2,25)\end{array}$} \\
\hline & Nữ & 255 & 65,6 & 134 & 34,4 & \\
\hline \multirow{2}{*}{$\begin{array}{l}\text { Trình độ } \\
\text { học vânn }\end{array}$} & $\leq \mathrm{THCS}$ & 226 & 58,1 & 163 & 41,9 & \multirow{2}{*}{$\begin{array}{c}0,27^{* *} \\
(0,14-0,53)\end{array}$} \\
\hline & $\geq \mathrm{PTTH}$ & 326 & 83,7 & 63 & 16,3 & \\
\hline \multirow{3}{*}{$\begin{array}{c}\text { Nghề } \\
\text { nghiệp }\end{array}$} & Nghề nông & 359 & 92,3 & 30 & 7,7 & \multirow{3}{*}{$\begin{array}{c}0,95 \\
(0,29-3,10)\end{array}$} \\
\hline & CBVC & 360 & 92,6 & 29 & 7,4 & \\
\hline & Nghề khác & 347 & 89,3 & 42 & 10,7 & \\
\hline \multirow{2}{*}{ Nơi cư trú } & Nông thôn & 236 & 60,7 & 153 & 39,3 & \multirow{2}{*}{$\begin{array}{c}3,70^{* *} \\
(1,89-7,25)\end{array}$} \\
\hline & Thành thị & 359 & 92,4 & 30 & 7,6 & \\
\hline \multirow{2}{*}{ Kinh tế } & Cậnnghèo,nghèo & 360 & 92,5 & 29 & 7,5 & \multirow{2}{*}{$\begin{array}{c}0,99 \\
(0,35-2,84)\end{array}$} \\
\hline & Không nghèo & 360 & 92,6 & 29 & 7,4 & \\
\hline \multirow{2}{*}{$\begin{array}{l}\text { Giai đoạn } \\
\text { bệnh }\end{array}$} & GĐ I,II & 103 & 26,4 & 286 & 73,6 & \multirow{2}{*}{$\begin{array}{c}0,62 \\
(0,34-1,11)\end{array}$} \\
\hline & GĐ III,IV & 143 & 36,7 & 246 & 63,3 & \\
\hline \multirow{2}{*}{ Diện chi trả } & BHYT & 372 & 95,7 & 17 & 4,3 & \multirow{3}{*}{$\begin{array}{c}1,86 \\
(0,24-14,81) \\
\end{array}$} \\
\hline & Tự chi trả & 359 & 92,2 & 30 & 7,8 & \\
\hline \multicolumn{6}{|c|}{$* * \mathrm{p}<0,05$} & \\
\hline
\end{tabular}

Có mối liên quan giữa nhu cầu CS xã hội của NB với trình độ học vấn, nơi cư trú $(p<0,05)$.Tỷ lệ $\mathrm{NB}$ có nhu cầu về xã hội ở nhóm trình độ học vấn $\geq \mathrm{PTTH}>$ nhóm $\leq \mathrm{THCS}(\mathrm{OR}=0,27 ; 95 \% \mathrm{Cl}=$ 0,14-0,53); nhóm ở nông thôn< nhóm thành thị $(\mathrm{OR}=3,70 ; 95 \% \mathrm{CI}=1,89-7,25)$.

\section{BÀN LUẦN}

1. Nhu câu chăm sóc của người bệnh sau phẫu thuật. Kết quả bảng 1 và 5 cho thấy nhu câu CS về y tế của NB cao $(86,9 \%)$, nhu câu muốn biết tình hình bệnh tật $92,3 \%$, muốn CS giảm đau 90,4\%, muốn biết cách phòng ngừa nhiễm trùng $85,7 \%$ cách sử dụng thuốc $89,2 \%$. Kết quả nghiên cứu của chúng tôi cao hơn tác giả Phan Thị Thanh Huyền (73,89\%).

Nhu cầu $C S$ về thể chất của $N B$ chiếm tỷ lệ khá cao là muốn hỗ trợ về vận động và tập luyện $(87,5 \%)$; muốn biết chế độ ăn, nghỉ ngơi phù hợp với bệnh (85,7\% và 84,3\%); muốn được hướng dẫn cách tự CS, TD và phòng bệnh
(78,3\%). Nghiên cứu của chúng tôi cao hơn Đặng Duy Quang (68,3\%). Hầu hết NB vào viện đều muốn được thay $Q$,áo và thay ga giường hàng ngày $(91,8 \%$ đến $98 \%)$. Nhu cầu CS thể chất trong nghiên cứu của chúng tôi $>$ tác giả Nguyễn Thị Bích Hợp cho thấy $73 \%$ cần được hỗ trợ các hoạt động chăm sóc cá nhân.

Đối với NB sau PT, vấn đề tâm lý rất quan trọng vì NB thường chịu đựng sự mất mát, đau đớn, biến dạng, tai biến do PT. Do đó, nhu cầu CS về tinh thần là rất lớn. Kết quả bảng 3 cho thấy nhu cầu CS tinh thần của NB khá cao là hỗ trợ kiến thức về bệnh $(88,5 \%)$; biết chi phí điều trị hằng ngày $(83,7 \%)$; hỗ trợ để khỏi lo lắng 
sau khi phẫu thuật $(84,3 \%)$; muốn có giấc ngủ ngon khi nằm viện $(79,8 \%)$. Kết quả này tương tự với Trần Ngọc Trung, hâuu hết NB khi vào viện đều muốn được tư vấn GDSK, đây là điều mà điều dưỡng cần lưu ý trong quá trình CSNB. Do đó, sự quan tâm, động viên, chia sẻ của điều dưỡng là hết sức quan trọng trong CS về tinh thần cho NB.

Bảng 4 và 5 cho thấy nhu cầu CS về xã hội của NB khá cao. Nhu cầu hố trợ viện phí là $91,6 \%$, muốn được an toàn khi nằm viện là $91,1 \%$, muốn được tôn trọng là $87,9 \%$, muốn được đối xử công bằng là $85,3 \%$. Như vậy, kết quả nghiên cứu của chúng tôi thấp hơn của tác giả Đặng Duy Quang $(79,0 \%)$.

2. Một số yếu tố liên quan đến nhu câu chăm sóc của người bệnh. Bảng 6 cho thấy có mối liên quan giữa tuổi, diện chi trả. Lứa tuổi khác nhau thường có những bệnh và quan niệm khác nhau về sức khỏe. Trong quá trình CS người điêu dưỡng cần chú ý những bệnh liên quan đến độ tuổi. Tỷ lệ có nhu cầu này ở nhóm $<60$ tuổi $<$ nhóm $\geq 60$ (là 79,1\% so với 90,9\%). Lý giải, nhóm tuổi cao thường có thể trạng và sức khoẻ kém hơn và có một số bệnh lý mắc kèm, nên họ thường mong nhận được những dịch vụ CS tổt giúp cải thiện tình trạng sức khoẻ và thể trạng của mình.

NB $<60$ tuổi có nhu cầu hỗ trợ tinh thần cao hơn NB $\geq 60$ tuổi $(94,3 \%$ và $86 \%)$. Có sự khác nhau về thái độ bộc lộ quan điểm về nhu cầu bản thân, người trẻ có xu hướng dễ dàng tiết lộ cảm xúc, nhu cầu, người già thường tin rằng bản thân có khả năng đối mặt, chịu đựng được các vấn đề về tâm lý, do đó họ thường giữ kín không muốn bộc lộ nhu cầu của mình. Nữ có nhu câu hố trợ tầm lý > nam $(96,5 \%$ và $85,1 \%)$ kết quả này tương đồng với nghiên cứu của Tabrizi và cộng sự[[8]. Nữ thường dễ nhạy cảm hơn nam với các vân đề tâm lý, họ thường gặp nhiêu căng thẳng hơn nam sau khi chẩn đoán ung thư, họ còn nhiều thứ phải lo lắng như con cái, gia đình, nhiều người có nguy cơ gặp rắc rối trong vấn đế hôn nhân, hạnh phúc... sau khi mắc ung thư [7]. Kết quả nghiên cứu nhu cầu ở NB giai đoạn III, IV > giai đoạn I,II $(94,5 \%$ so với $81,8 \%)$. Những NB có giai đoạn muộn thường có tâm lý lo lắng hơn điều này có thể đấn đến nhu cầu tâm lý $>$ những NB giai đoạn sớm hơn.

Nhu câu CS thể chất như vệ sinh cá nhân, hỗ trợ bài tiết, hỗ trợ mặc quần áo thường do người nhà đảm nhận. Nhu cầu muốn hướng dẫn vận động, tập luyện; chế độ nghỉ ngơi,ăn uống phù hợp; hướng dẫn tự CS, TD, phòng bệnh thì cần có sự giúp đõ̃ từ nhân viên y tế. NB nữ có nhu cầu này $>$ nam $(98,8 \%$ và $68,2 \%)$. Một số nghiên cữu cũng cho kết quả tương đồng [5],[6]. Nhóm NB có trình độ học vấn $\leq$ THCS < nhóm trình độ $\geq$ PTTH (92,5\% và 60,4\%).

Kết quả bảng 9 , có mối liên quan giữa nhu cầu CS xã hội của NB với trình độ học vấn và nơi cư trú $(p<0,05)$. Tỷ lệ NB có nhu cầu xã hội ở nhóm có trình độ học vấn $\geq$ PTTH là $83,7 \%$ cao hơn có ý nghĩa thống kê so với nhóm NB có trình độ học vấn $\leq \operatorname{THCS}(58,1 \%)$; nhóm thành thị là $92,4 \%$ cao hơn có ý nghĩa thống kê so với nhóm ở nông thôn $(60,7 \%)$.

\section{KẾT LUẬN}

\section{Nhu câu chăm sóc của người bệnh} sau phẫu thuật tại Bệnh viện K. Nhu cầu chăm sóc về y tế và chăm sóc về xã hội của NB khá cao $(85,0 \%$ và $79,0 \%)$. Nhu cầu chăm sóc về thể chất và tinh thần thấp hơn $(43,8 \%$ và $47,6 \%)$.

\section{Các yếu tố liên quan tới nhu câu chăm} sóc của người bệnh

- Có mối liên quan giữa nhu cầu CS y tế với nhóm tuổi và diện chi trả. Không có mối liên quan giữa nhu cầu CS y tế với một số đặc điểm như giới, trình độ học vấn, nghề nghiệp, nơi cư trú và điều kiện kinh tế $(p>0,05)$.

- Có mối liên quan giữa nhu câu CS tinh thần với nhóm tuổi, giới và giai đoạn bệnh. Không có mối liên quan giữa nhu cầu CS về tinh thần với một số đặc điểm như trình độ học vấn, nghề nghiệp, nới cư trú và kinh tế, diện chi trả $(p>0,05)$.

- Có mối liên quan giữa nhu cầu CS thể chất với giới và trình độ học vấn. Không có mối liên quan giữa nhu câu CS về thể chất với một số đặc điểm như nhóm tuổi, nghề nghiệp, nơi cư trú và kinh tế, diện chi trả $(p>0,05)$.

- Có mối liên quan giữa nhu cầu CS xã hội của người bệnh với trình độ học vấn, nơi cư trú. Không có mối liên quan giửa nhu cầu CS xã hội với một số đặc điểm như nhóm tuổi, giới, nghề nghiệp, kinh tế và diện chi trả $(p>0,05)$.

\section{TÀl LIÊU THAM KHẢO}

1. Nguyễn Thị Bích Hợp (2005), "Đánh giá đáp ứng nhu cầu cơ bản trong chăm sóc toàn diện tại Khoa Hồi sức cấp cứu Bệnh viện $C$ Đà nẵng", Kỷy yếu các đồ tài nghiên cứu khoa học điêuu dướng toàn quốc lầnthứ II, tr. $90-95$.

2. Phan Thị Thanh Huyên (2010), Khảo sát nhu câuu chăm sóc toàn diện và thực hành chăm sóc toàn diệntrên người bệnh đái tháo đường týp 2 tại Bệnh viện Trung ương Huế, Luận văn tốt nghiệp cử nhân điêu dướng, Trường Đại học Y Dược Huể. 
3. Bùi Thị Ngà và cộng sự (2012), "Đánh giá chất lương chăm sóc ngưới bệnh toàn diên của người điểu dưỡng bênh viện Ỳ học Cổ truyền Trung ương", Tạp chí nghiên cứu Y dược học cổ truyền Viêt Nam, số 33, tr 58-63.

4. Nguyê̂n Trường Sơn (2010), "Tìm hiểu cảm xúc và nhu câu chăm sóc về mặt tinh thân của người bênh ở bênh viên trường đại học $Y$-Dược Huế" ${ }^{\prime \prime}$ Kỷ yểu đề tài nghiên cứu khoa học điêu dưỡng Hội nghi khoahoc điều dưỡng toàn quốc lần thứ IV, tr $208-216$.

5. Trân Ngọc Trung (2012), Đánh giá hoạt động chăm sóc người bệnh của điều dưỡng tại khối Nội và khối Ngoại Bệnh viện Đa khoa tỉnh Lâm Đồng, năm 2012, Luận văn thạc sỹ quản lý bệnh viện, Trường Đai hoc Y tế Công cônng, Hà Nối.

6. Baum et ai (2013), The potential for multidisciplinary primary health care services to take action on the social determinants of health: actions and constraints, BMC Public Health: 13:460.

7. Happell Brenda, Platania-Phung Chris, Scott David (2013), Physical health care for people with mental illness: Training needs for nurses, Nurse Education Today, 33, pp. 396-401

\section{THỰC TRẠNG HộI CHỨNG SẢNG Ở NGƯỜI TỪ 60 TUỔI TRỞ LÊN TẠI KHOA CẨP CỨU BỆNH VIÊ̂N LÃO KHOA TRUNG ƯƠNG}

\section{TÓM TẮT}

Chúng tôi thực hiện nghiên cứu với mục tiêu mô tả thực trang hội chứng sảng ở người bênh từ 60 tuổi trở lên tại Khoa cấp cứu bệnh viện Lão khoa Trung ương. Đây là một nghiên cứu mô tả cắt ngang, thực hiện trên 106 bệnh nhân từ 60 tuổi trở lển đến khám và điều trị tại Khoa cấp cứu bệnh viện Lão khoa Trung ương và được chẩn đoán hội chứng sảng theo tiêu chuẩn chẩn đoán của ICD 10. Kết quả: Người bênh có hội chứng sảng thường gặp là nhóm tuổi $80-89$, tuổi trung bình là $78,3 \pm 10,9$, nam giới gặp nhiều hớn nữ giới $(52,8 \%$ và $47,2 \%)$. Phần lớn bệnh nhân đang sống cùng gia đình $(68,9 \%)$, chỉ có 2 trường hợp sống trong nhà dưỡng lão $(1,9 \%)$. Đa số người bệnh có biểu hiện suy giảm thị giác $(87,7 \%)$ và suy giảm thính giác $(81,1 \%)$. Triệu chứng gặp nhiều nhất là biểu hiện rối loạn định hướng không gian và giảm trí nhớ gần với tỉ lệ là $89,6 \%$. Tiếp đó đến biểu hiện giảm khả năng duy trì sự chú ý $(61,3 \%)$. Ít gặp nhất là biểu hiên đảo ngước chu kì thức ngủ (24,5\%).

Từ khoá: hội chứng sảng; người già.

\section{SUMMARY}

SITUATION OF DELIRIUM SYNDROME AMONG PATIENTS AGED 60 YEARS AND OLDER IN EMERGENCY DEPARTMENT IN NATIONAL GERIATRIC HOSPITAL

Our study aimed to describe the situation of delirium syndrome among patients aged 60 years and older in Emergency Department in National Geriatric Hospital. This is a cross-sectional descriptive study, including 106 patients aged 60 years and older who came for examination and treatment in Emergency

\footnotetext{
${ }^{1}$ Đai hoc Y Hà Nôi

2 Viện Sức Khỏe Tâm Thần - Bênh Viên Bach Mai

Chịu trách nhiệm chính: Trần Nguyễn Ngọc

Email: trannguyenngoc@hmu.edu.vn

Ngày nhận bài: 10.9.2021

Ngày phản biên khoa hoc: 2.11.2021

Ngày duyệt bài: 12.11.2021
}

\begin{abstract}
Dương Minh Tâm ${ }^{1,2}$, Trần Nguyễn Ngọc ${ }^{1,2}$
Department in National Geriatric Hospital, were diagnosed with delirium syndrome according to diagnostic criteria of ICD 10. Results: Most of patients had delirium symptoms were in the age group of $80-$ 89 years old, the mean age was $78.3 \pm 10.9$. There was a small gender difference, men were more common than women (52.8\% and $47.2 \%)$. Most elderly people lived with their families $(68.9 \%)$. There were 2 cases livedg in the nursing home (1.9\%). Most of the patients had visual impairment $(87.7 \%)$ and hearing loss $(81.1 \%)$. The most common symptoms were spatial orientation disorder and memory loss, with the same rate of $89.6 \%$, followed by the decrease in attention span (61.3\%). The least common was sleep-wake cycle reversal (24.5\%).

Keywords: delirium syndrome; elderly people.
\end{abstract}

\section{I. ĐĂT VẤN ĐỀ}

Hội chứng sảng là một hội chứng phổ biến ở những người cao tuổi ở nhóm bênh nhân nội trú. Khoa cấp cứu đóng vai trò trung tâm trong một bệnh viện và là cửa ngõ đầu vào cho phần lớn các trường hợp nhập viên. Ước tính có tới 7 20\% bênh nhẩn cao tuổi có hội chứng sảng được nhập vào khoa cấp cứu. ${ }^{1}$ Tuy nhiên, các nghiên cứu cho thấy có tới $30 \%$ đến $67 \%$ người bệnh cao tuổi có hội chứng sảng không được phát hiện trên lâm sàng. ${ }^{2}$ Hiện nay có nhiều cách để chia nhóm người cao tuổi. Người giai đoạn đầu tuổi già từ 60 trở lên hoặc 65 - 74 tuổi, người giai đoann giữa tuổi già từ 70 tuổi trở lên hoăc 75 - 84 tuổi và người giai đoạn cuối tuổi già từ 80 tuổi trở lên hoặc từ 85 tuổi trở lên. Trong nghiên cứu này, chúng tôi muốn nghiên cứu để làm rõ thực trang của hội chứng sảng ở nhóm tuổi từ 60 trở lên tại khoa cấp cứu bênh viên Lão khoa trung ương. Mục tiêu của nghiên cứu là "mô tả thực trạng hội chứng sảng ở người từ 60 trở lên tại khoa cấp cứu bệnh viện Lão khoa trung ương". 